\title{
- Plataforma Base Covid-19 e os Reflexos no Direito do Trabalho: uma construção colaborativa das bibliotecas da Justiça do Trabalho
}

\author{
Platform Covid-19 and the Reflections on Labor Law: a \\ collaborative construction of the Labor Justice libraries
}

\begin{abstract}
Anastácia Oliveiraa,*
Cristiane Ferreira de Souzab (D)

Adriana Godoy da Silveira Sarmentoc ${ }^{c}$

RESUMO: Este relato de experiência descreve como foi concebida a ideia da plataforma colaborativa que reúne a doutrina e a legislação sobre os impactos da Covid-19 no Direito Material e Processual do Trabalho e nas relações trabalhistas. Para isso, analisa o propósito das bibliotecas especializadas correlacionandoo com as características das bibliotecas trabalhistas. Narra a história das bibliotecas participantes, contextualizando as unidades de informação na história da Justiça do Trabalho. Argumenta que o trabalho colaborativo permite o alcance de maiores resultados, a partir do exame dos conceitos de colaboração bibliotecária. Relata o histórico de colaboração das bibliotecas da Justiça do Trabalho, enfatizando as ações e os encontros institucionais. Explica a escolha da ferramenta que hospeda a plataforma, assim como as suas vantagens e limitações. Descreve como foram estabelecidas as fontes de informação a serem monitoradas, as palavras-chave inseridas na busca e os critérios de seleção das fontes digitais. Apresenta as formas de propaganda da plataforma e as estatísticas de uso. Finaliza demonstrando os próximos passos e as pretensões das bibliotecas participantes, reforçando a importância histórica do armazenamento das informações referenciadas.
\end{abstract}

Palavras-chave: Plataforma Colaborativa; Informação Jurídica; Covid-19; Biblioteca Jurídica; Rede de Bibliotecas.

ABSTRACT: Such platform collects the doctrine and legislation about the impacts of Covid-19 on Material and Procedural Labor Law and labor relations. The report analyzes the purpose of specialized libraries, correlating with the characteristics of labor libraries. Besides, the report narrates the history of the participating libraries, contextualizing the information units in the history of Labor Justice. It is argued that collaborative work allows the achievement of greater results, based on an examination of the concepts of library collaboration. The history of collaboration of the Labor Justice libraries is analysed, emphasizing the actions taken and institutional meetings. One of its purposes is to explain the choice of the tool that hosts the platform, as well as its advantages and limitations. It describes how the sources of information should be monitored, the keywords entered in the search and the criteria for selecting digital sources were established. The report presents the platform's advertising forms and usage statistics. It concludes by demonstrating the next steps and intentions of the participating libraries, reinforcing the historical importance of storing the referenced information.

Keywords: Collaborative Platform; Legal Information; Covid-19; Law Library; Library Network.

\footnotetext{
a Tribunal Regional do Trabalho da $10^{\text {a }}$ Região, Brasília, DF, Brasil.

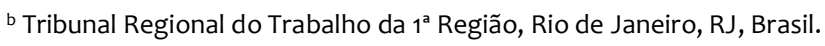

c Tribunal Regional do Trabalho da 4 a Região, Porto Alegre, RS, Brasil.

*Correspondência para/Correspondence to: Anastácia Freitas de Oliveira. E-mail: anastacia.oliveira@trt10.jus.br.

Recebido em/Received: 15/08/2020; Aprovado em/Approved: 28/12/2020.
}

Artigo publicado em acesso aberto sob licença CC BY 4.0 Internacional $(9)$ 


\section{INTRODUÇÃO}

Cientes de que os impactos da pandemia da COVID-19 atingiram todas as esferas da sociedade, inclusive o Direito do Trabalho, as bibliotecas dos Tribunais Regionais do Trabalho (TRT) e do Tribunal Superior do Trabalho (TST) reuniram esforços para gerar um documento colaborativo para auxiliar os bibliotecários na resposta de solicitações de pesquisa. O objetivo principal é manter os usuários atualizados em relação às transformações decorrentes da pandemia. Desta forma, foi empreendido um esforço colaborativo para localizar as principais fontes e disponibilizá-las em uma única plataforma, com resumo e palavras-chave que facilitem a recuperação.

Em função da velocidade das mudanças legislativas, não é possível esperar a publicação de um livro para que o usuário possa se inteirar sobre o que está acontecendo. Além disso, os canais informacionais mudaram. Reflexões e debates agora são disseminados por lives e seminários online.

Com seus acervos de livros físicos fechados para acesso e circulação de itens, os bibliotecários buscaram alternativas para continuar desempenhando sua função de atender às necessidades informacionais dos usuários. Por esse motivo, foi concebida uma plataforma colaborativa, que se configura como uma base de dados referencial.

Este artigo descreve a experiência da concepção dessa plataforma colaborativa. Para isso, explicará o contexto das bibliotecas participantes, analisando o papel das bibliotecas especializadas e, mais especificamente, as da Justiça do Trabalho. Em seguida, descreve a Base Covid-19 e os reflexos no Direito do Trabalho', informando os critérios de inclusão de conteúdos, o controle de vocabulário, o marketing e as estatísticas de uso. Finaliza expondo quais são os próximos passos pretendidos para a plataforma.

\section{A BIBLIOTECA ESPECIALIZADA E A JUSTIÇA DO TRABALHO}

Diferentemente das bibliotecas públicas e universitárias, em que são disponibilizados materiais informacionais de diversos campos do conhecimento para o atendimento das necessidades informacionais de um público heterogêneo, a biblioteca especializada, conforme Silva e Freire (2012), vêm da união entre usuário e acervo: ela é uma unidade de informação com acervo especializado destinado à satisfação das necessidades informacionais de um público específico.

Outra característica da biblioteca especializada é o acervo seletivo. De acordo com Volpato e Borenstein (2000, p. 88):

\footnotetext{
As bibliotecas especializadas têm características peculiares, principalmente em relação a um acervo mais seletivo e atual, se comparado aos modelos de bibliotecas tradicionais, como bibliotecas públicas e escolares, e mesmo às bibliotecas universitárias, com seus acervos mais diversificados em termos de áreas de conhecimento.
}

Tinôco (2017) caracteriza as bibliotecas especializadas a partir de seis aspectos: localização, limitação de assunto, tipo de material, tipo de usuário, tamanho e função. A partir de parte das características declaradas pela autora, apresentamos as características das bibliotecas especializadas dos Tribunais do Trabalho:

${ }^{1}$ Disponível em: https://sites.google.com/view/covidleistrabalhistas/início 
- Localização: bibliotecas especializadas estão vinculadas a instituições públicas ou privadas e devem respeitar a cultura da organização às quais são vinculadas, assim como demonstrar seus valores e objetivos. As bibliotecas estão vinculadas aos Tribunais Regionais do Trabalho e ao Tribunal Superior do Trabalho e, assim como as demais bibliotecas especializadas, devem apoiar a instituição no cumprimento de sua missão.

- Limitação de assunto: a coleção é quase exclusivamente dedicada à literatura de um determinado assunto, cobrindo assuntos específicos tão exaustivamente quanto possível. No caso das bibliotecas trabalhistas, é necessário que a coleção incorpore parte significativa da produção intelectual sobre o Direito Material e Processual do Trabalho.

- Tipo de material: algumas bibliotecas são especializadas em um tipo de material, como mapas e jornais. No entanto, nas bibliotecas trabalhistas há vários tipos de materiais impressos e digitais, predominantemente periódicos e livros físicos ou digitais.

- Tipo de usuário: a biblioteca serve a um seleto grupo de usuários associados à organização da qual a biblioteca faz parte. No caso das bibliotecas trabalhistas, seriam os servidores e magistrados e, em algumas unidades, estagiários, terceirizados e a comunidade jurídica local, tais como, advogados e estudantes.

- Tamanho: podem variar entre um tamanho grande ou coleções de pequeno porte muito especializadas. Assim como as demais bibliotecas especializadas, há bibliotecas trabalhistas de diversos tamanhos.

- Função: tem por objetivo fornecer informação com fins imediatos e utilitários. No contexto das bibliotecas especializadas, as bibliotecas trabalhistas são caracterizadas como Bibliotecas Jurídicas. Para Oliveira (2019, p. 22) a biblioteca jurídica é uma: "unidade de informação que reúne, organiza e disponibiliza material informacional relativo à doutrina, jurisprudência e legislação a fim de apoiar a tomada de decisão, sobretudo decisões relativas à prestação jurisdicional”.

Mesmo com a redução significativa do trabalho presencial nas cortes trabalhistas, a realização de atividades administrativas e julgamentos prosseguem a distância. De acordo com o Tribunal Superior do Trabalho (TST), no período de janeiro a maio de 2020, foram mais de 7,7 mil novas ações ordinárias classificadas com o assunto Covid19 nas Varas do Trabalho e nos Tribunais Regionais do Trabalho (BRASIL, 2020i).

A tendência de busca de alguns termos também pode prever futuras necessidades de informação. Para saber o que tem sido buscado por brasileiros, utilizamos o Google Trends, "que fornece acesso a uma amostra essencialmente não filtrada de pedidos de pesquisa reais efetuados à Google" (TRENDS, 2020).

Foi possível observar que os termos "fato príncipe", "teletrabalho", "doença ocupacional", "trabalhador autônomo", "trabalhador informal", "home office", "redução de jornada", "redução de salário" e "auxílio-doença" tiveram o maior índice de busca no Brasil nos meses de março e abril de 2020, representando o pico de busca desses termos dos últimos 5 anos.

Diante dessa imensa procura, as bibliotecas trabalhistas se organizaram para sanar as demandas informacionais explícitas e latentes dos magistrados e servidores, reunindo análises de especialistas e centralizando a legislação relacionada em uma única plataforma. 


\section{A JUSTIÇA DO TRABALHO}

A história da Justiça do Trabalho no Brasil teve sua origem definida a partir da criação do Conselho Nacional do Trabalho (CNT) por meio do Decreto $n^{\circ} 16.027$, de 30 de abril de 1923, vinculado ao Poder Executivo Federal. Originalmente sendo um órgão de caráter consultivo (BRASIL, 2020h).

A partir de 1946, a Justiça do Trabalho passou a ter como órgãos o Tribunal Superior do Trabalho (antigo CNT), os Tribunais Regionais do Trabalho (antigos Conselhos Regionais) e as Juntas de Conciliação e Julgamento, que a partir de Emenda Constitucional $n^{\circ}$ 24/99, passaram a ser denominadas como Varas de Trabalho. (BRASIL, 2020h).

\section{AS BIBLIOTECAS DA JUSTIÇA DO TRABALHO E O TRABALHO COLABORATIVO E COOPERATIVO}

Cada um dos Tribunais Regionais do Trabalho, bem como o Tribunal Superior do Trabalho possuem em sua estrutura uma biblioteca especializada para atender às demandas informacionais de seus usuários, totalizando, atualmente, 25 unidades de informação.

As 25 bibliotecas da Justiça do Trabalho são independentes uma da outra e têm estrutura organizacional própria, sendo que o que as une em uma perspectiva de colaboração é a especificidade do ramo do Direito a que estão ligadas: Direito Material e Processual do Trabalho.

$\mathrm{Na}$ literatura, os conceitos de colaboração e cooperação muitas vezes são usados como sinônimos, porém, podem ser considerados por alguns autores como conceitos distintos.

Para Winckler e Molina (2011, p. 1): "a cooperação ocorre em nível horizontal com ganhos para ambos os parceiros, e a colaboração aparece em nível vertical ou horizontal, como apoio de uma organização a outra".

Os autores Alves e Barbosa (2010, p. 2) salientam que os:

[...] sistemas colaborativos são construídos ou adotados pelas organizações com a finalidade de promover a interação entre grupos e/ou indivíduos e, dessa forma, favorecer o compartilhamento da informação sem que haja necessidade de os envolvidos estarem no mesmo local. (ALVES; BARBOSA, 2010)

Dessa forma, as bibliotecas que tem um objetivo comum se organizam em redes para colaborar.

A colaboração entre os setores é fundamental para realização de projetos e iniciativas, portanto é necessário que as bibliotecas construam redes de colaboração nas quais possam desenvolver e implantar ações que podem modificar significativamente o acesso às informações aos seus usuários (ARAÚJO, 2019, p. 66).

Para Araújo (2019, p. 63) em rede "podem ser construídas ações que venham a contribuir para o bem do coletivo".

Com posse do máximo de informação possível por intermédio da colaboração, as bibliotecas poderão garantir que a comunidade 
usuária acesse as informações que sozinhas elas não teriam condições de fornecer (ARAÚJO, 2019, p. 67).

Portanto, verifica-se a importância de as bibliotecas trabalharem juntas para enfrentar melhor os desafios e alcançar objetivos comuns.

Desde a década de 1990, cientes da importância de compartilharem conhecimentos, informações e experiências para o alcance de maiores e melhores resultados, as bibliotecas da Justiça do Trabalho buscam desenvolver trabalhos colaborativos e cooperativos.

Entre as ações de trabalho colaborativos e cooperativos das bibliotecas da Justiça do Trabalho merecem destaque: os Encontros de Bibliotecários da Justiça do Trabalho; a adoção do Thesaurus do Direito do Trabalho (TEJUT), e de um mesmo sistema de automação (Siabi); a criação de um Catálogo de Autoridades; oferecimento de cursos de atualização; elaboração de atos normativos com padrões para a rede. Também foram estabelecidos canais para compartilhamento de melhores práticas entre as bibliotecas cooperantes. Atualmente está sendo elaborado o projeto de criação do novo Thesaurus da Justiça do Trabalho.

Em 2020, durante a pandemia, as bibliotecas trabalharam com a catalogação e indexação de materiais digitais, com a revisão, conforme as normas da ABNT, dos artigos que serão publicados nos periódicos oficiais dos TRTs, com o planejamento de novos serviços, de novos produtos e com o estudo sobre a reabertura da biblioteca e suas implicações, etc. Um período de muito trabalho, de novos desafios e de novas oportunidades.

As bibliotecas elaboraram um ato normativo para formalização da Rede que passou a se chamar Rede de Bibliotecas da Justiça do Trabalho (Rebijutra), homologado pelo Conselho Superior da Justiça do Trabalho no Ato Conjunto TST.CSJT n49/2020 e um outro Ato para o tratamento, a conservação e a guarda de acervos raros e especiais das bibliotecas da Justiça do Trabalho que se encontra sob apreciação pelos órgãos competentes.

Para melhoria dos trabalhos conjuntos foram criados três Grupos de Trabalho (GTs): GT de Aquisição, GT de Referência Virtual e GT de Reabertura da Biblioteca após quarentena.

Na Justiça do Trabalho o número de ações trabalhistas relacionadas à Covid-19 tem aumentado significativamente. Este aumento reflete-se na necessidade que os usuários internos (magistrados e servidores) e externos (advogados, partes e estudantes) têm tido por informações atualizadas e confiáveis relacionadas ao assunto. Dessa forma, as bibliotecas dos TRTs estão precisando se reinventar e, mesmo sem acesso a um acervo físico, buscar parcerias e formas de conseguir a informação necessária para o usuário (SARMENTO, 2020b).

Desde março de 2020 até a aprovação deste artigo, por exemplo, a Biblioteca do TRT4 realizou mais de 2.800 pesquisas a distância. Estes números não refletem, entretanto, o trabalho que as buscas para se chegar a essas informações demandam. Se no trabalho presencial o bibliotecário pode mostrar uma estante com o assunto necessário e o usuário buscar a informação, no trabalho remoto, às vezes, são necessários mais de 30 contatos para se chegar o mais perto possível da informação de que o usuário precisa.

Diante do cenário acima exposto, foi criada a Plataforma Colaborativa: Base COVID-19 e os reflexos no Direito do Trabalho. 


\section{A iniciativa e o histórico de adesão}

Uma das missões da biblioteca especializada é fornecer informações específicas para um público que atua em determinada área, e, por sua vez, a biblioteca jurídica tem como objetivo apoiar a tomada de decisão, com ênfase no embasamento a decisões judiciais. Por isso, não seria interessante que as bibliotecas dos Tribunais Regionais do Trabalho fossem indiferentes às novas formas de disponibilização das informações jurídicas, sobretudo da doutrina.

Com o intuito de maximizar esforços e aumentar a eficiência, foi estimulado o trabalho em colaboração para reunir em uma única plataforma a doutrina e a legislação publicada a respeito dos impactos da pandemia de Covid-19 nas relações de trabalho.

O conteúdo reunido consiste em artigos, podcasts, e-books, webinars, lives, infográficos e demais expressões em que especialistas se debruçam sobre os impactos da pandemia nas relações de trabalho e do Direito Processual do Trabalho.

É importante ressaltar que essas novas expressões como webinar, podcast, infográfico e live não eram tradicionalmente incluídas nos catálogos das bibliotecas. No entanto, são essas as novas mídias utilizadas em função da impossibilidade de realização de palestras, aulas e demais encontros presenciais.

Parte do conhecimento reunido foi produzido por magistrados e/ou especialistas dos Tribunais ou a convite das cortes. Por exemplo, em levantamento realizado em julho, verificou-se que 148 lives foram promovidas no YouTube em canais de Escolas Judiciais ou de Tribunais Regionais do Trabalho.

Por remeter os usuários à fonte original, a Plataforma colaborativa: Base Covid-19 e os reflexos no Direito do Trabalho é uma base de dados bibliográficos referencial, ou seja, inclui:

[...] citações ou referências bibliográficas e, às vezes, resumos de trabalhos publicados. Informam ao usuário sobre o que foi publicado e onde se publicou (por exemplo, se num periódico, nos anais de um congresso) e, na hipótese de a base conter resumos, apresentarão uma síntese do conteúdo original (ROWLEY, 2002, p. 110).

O início da reunião dos dados foi no mês de abril de 2020, por iniciativa da Biblioteca Desembargador Fernando Américo Veiga Damasceno, do TRT10. As primeiras bibliotecas participantes foram as bibliotecas do TRT1, TRT2 e TRT3. A partir da colaboração dessas, foi possível definir melhor o escopo e a cobertura da base, que inicialmente foram pensados para incluir apenas fontes gratuitas de informação. Com a entrada da biblioteca do TRT 4, que já produzia boletim específico sobre a Covid-19, que reúne, dentre outros materiais, a legislação federal, introduziu-se a legislação na base colaborativa.

Até o momento, 10 bibliotecas colaboram efetivamente com a alimentação da Plataforma colaborativa Covid-19, a qual pode, futuramente, ter uma adesão maior.

As bibliotecas que colaboram com a Plataforma são: Biblioteca do Tribunal Superior do Trabalho, Biblioteca do TRT da $1^{\text {a }}$ Região (jurisdição no Estado do Rio de Janeiro), Biblioteca do TRT da $2^{a}$ Região (jurisdição na cidade de São Paulo), Biblioteca do TRT da $3^{\text {a }}$ Região (jurisdição no Estado de Minas Gerais), Biblioteca do TRT da $4^{\text {a }}$ Região (jurisdição no Estado do Rio Grande do Sul), Biblioteca da $6^{a}$ Região (jurisdição no Estado de Pernambuco), Biblioteca do TRT da $7^{\text {a }}$ Região (jurisdição no Estado do Ceará), Biblioteca do TRT da $10^{a}$ Região (jurisdição nos Estados do Distrito Federal e 
Tocantins), Biblioteca do TRT da $12^{\mathrm{a}}$ Região (jurisdição em Santa Catarina) e Biblioteca

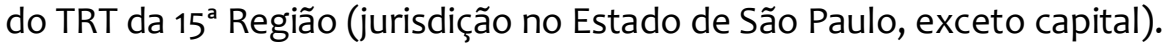

Em razão da necessidade de todas as bibliotecas participantes alimentarem a plataforma de forma autônoma, descentralizada e em tempo real, adotou-se uma planilha do Google. O Google sites permite a criação de sites com facilidade, mesmo sem conhecimento de programação ou design. Além disso, o conteúdo é responsivo, ou seja, a página pode ser visualizada sem a necessidade de adaptações para tablets e dispositivos móveis (GOOGLE, 2020).

Embora seja de fácil alimentação e customização, a principal limitação da plataforma é a impossibilidade de realização de pesquisas. O usuário deve entrar na planilha e usar as teclas de atalho ctrl+f para localizar a informação que deseja. Buscando amenizar o problema da recuperação da informação, os bibliotecários fazem um novo resumo e atribuem novas palavras-chave.

\section{Critérios de seleção dos materiais e monitoramento das fontes}

Diante da grande quantidade de informações geradas, mesmo em um tema especializado, foi preciso delimitar quais seriam as fontes que seriam monitoradas e quais materiais seriam listados.

O uso de veículos de informação até o momento não registrados por grandes repositórios, como lives e podcasts, foi um grande desafio. Conforme já mencionado, a pandemia fez com que periódicos e livros, que por sua natureza demandam um certo tempo para sua publicação, fossem preteridos em favor do uso de mídias audiovisuais que eventualmente permitam a participação do público.

Por esse motivo, foi necessário desenvolver um processo de seleção diferenciado dos demais repositórios e buscadores convencionais, devido a diferença do suporte, ausência de índices de qualidade para essas fontes e impossibilidade de importação automática por protocolos de comunicação.

Como critérios de análise e delimitação, foi necessário retomar os critérios de conteúdo e adequação ao usuário usados no desenvolvimento de coleções.

De acordo com Vergueiro (2010) e Andrade e Vergueiro (1996), os critérios de conteúdo para uma fonte de informação são:

- Autoridade: qualidade do material através da reputação do seu autor, editora ou patrocinador.

- Precisão: o quanto a informação veiculada é exata, rigorosa e correta.

- Imparcialidade: verifica-se que os assuntos dos documentos são apresentados sem favoritismo a algum ponto de vista.

- Atualidade: critério decisivo em algumas bibliotecas e determinadas áreas do conhecimento. Os bibliotecários deverão manter-se atentos a novas edições ou revisões de obras já publicadas.

- Cobertura/tratamento: se o texto entra em detalhes suficientes e se todos os aspectos importantes foram cobertos.

Já os critérios de adequação ao usuário são:

- Conveniência: elementos visuais e nível de vocabulário compreensível ao usuário. 
- Idioma: língua do documento acessível aos usuários da coleção. No caso da plataforma, podem ser admitidos conteúdos nos idiomas português, inglês e espanhol.

- Relevância/interesse: documento relevante para a experiência do usuário, sendo-lhe de alguma utilidade.

O critério de autoridade é o que se sobressai para a seleção de materiais. Foram incluídos autores renomados da área e que costumam ser demandados pelos usuários em relação a livros físicos ou bastante buscados em base de dados digitais. Magistrados e membros do Ministério Público também foram considerados no critério de autoridade de autor.

Em relação ao critério de autoridade da fonte, foram considerados conteúdos dos Tribunais Regionais e do Superior do Trabalho, da Escola Superior do Ministério Público da União (ESMPU), de informativos jurídicos renomados, de canais de associações profissionais nacional e internacionais, de institutos célebres, da Academia de Direito do Trabalho, de páginas e de periódicos de editoras especializadas.

No caso de páginas pessoais, blogs e demais fontes consideradas, a princípio, informais, foram combinados os critérios de autoridade e de fonte de autor: foram incluídos apenas aqueles em que o autor era renomado e/ou magistrado. É importante ressaltar que a escolha dessas fontes foi supervisionada por uma bacharel em Direito que faz parte da equipe da Biblioteca do TRT1. Dessa forma, foi possível aproximar os bibliotecários de fontes informais relevantes para os profissionais do Direito.

Fontes tradicionalmente consideradas voltadas para o público acadêmico também estão sendo monitoradas. Estão sendo incluídos na base aqueles materiais que abordam tanto aspectos trabalhistas quanto de saúde, sociológicos, dentre outras áreas do conhecimento, desde que dentro do escopo da base.

A partir da análise da demanda dos usuários no serviço de referência e do debate entre os bibliotecários envolvidos, foram selecionadas fontes iniciais que deveriam ser consultadas periodicamente para a extração de dados para a plataforma. Além disso, houve a avaliação da viabilidade da curadoria dos metadados, visto que o material inserido deve ser acompanhado de resumo e palavras-chave elaborados pelo bibliotecário.

Como instrumento de coleta de dados, foram definidas palavras-chave como parâmetro para a busca nas fontes pré-definidas, após consulta em vocabulários controlados como WebThes e LexML. Os termos pesquisados são: Coronavírus (e variações como Covid19, Covid-19, SARS-Cov-2, 2019-nCoV, Novo Coronavírus); Relações de trabalho; Relações de Emprego; Pandemia; Calamidade pública; Contrato de trabalho; Teletrabalho; Trabalho remoto; Home office; Crise do coronavírus; crise do COVID-19; Decreto legislativo 6/2020; Medida provisória 958/2020; Medida provisória 955/2020; Medida provisória 927/2020; Medida provisória 928/2020; Medida provisória 936/2020; Medida provisória 944/2020; Medida provisória 946/2020; Teoria da imprevisão; Fato do príncipe (ou Factum principis).

Atualmente são monitoradas 27 fontes, detalhadas no apêndice. Cada biblioteca comprometeu-se a incluir o conteúdo pertinente produzido por seu Tribunal, como revistas institucionais e lives, além de acompanhar outras fontes. A periodicidade varia de acordo com a disponibilidade do bibliotecário de cada equipe. De abril até a publicação deste artigo, foram incluídos mais de 800 itens na plataforma. 


\section{Marketing e Estatísticas de uso}

De acordo com o Google Analytics, desde o dia 4 de maio de 2020 (data da primeira divulgação da plataforma para os usuários do TRT10) até o dia 13 de dezembro do mesmo ano, a página foi visualizada 10.680 vezes. A maioria das visualizações são oriundas do Brasil, mas a lista de países conta com visualizações de Estados Unidos, Portugal e países latinos como Argentina e Colômbia.

O Estado de São Paulo é o que concentra o maior número de visitas ao site, seguido de Rio de Janeiro e Minas Gerais. Ocupam a quarta posição Rio Grande do Sul, a quinta o Distrito Federal. Pode-se inferir que a divulgação das bibliotecas participantes da iniciativa impulsiona o uso nessas regiões. O mapa indica que já houve acesso em todos os estados brasileiros.

Além dos canais de comunicação institucionais, houve a propaganda em outros veículos. O TRT10, por exemplo, divulgou a plataforma nos grupos de whatsapp de magistrados e servidores e também no site oficial do Grupo de Informação e Documentação Jurídicas do Distrito Federal (GIDJ-DF). Já o TRT2, menciona a plataforma nas lives do Tribunal em forma de comentários. Por sua vez, o TRT3 incluiu o link da plataforma na revista temática da corte sobre a Covid-19. O presidente da Comissão de Biblioteca do TRT1 divulgou a plataforma junto à Associação de Magistrados da Justiça do Trabalho da $1^{\mathrm{a}}$ Região (AMATRA 1). A plataforma também foi noticiada no portal do Conselho Nacional de Justiça (CNJ). O TST divulgou a notícia em sua página principal, o que ensejou a divulgação na rádio Justiça. Também houve menção no relatório Monitoring the Legal Response to COVID-19 in Latin America and the Caribbean, que apresenta informações jurídicas e governamentais relacionadas à pandemia elaboradas e monitoradas por bibliotecários jurídicos.

\section{CONCLUSÃO}

A Rede de Bibliotecas da Justiça do Trabalho (Rebijutra) vem realizando diversas ações colaborativas bem-sucedidas. A plataforma referencial "Covid-19 e os Reflexos no Direito do Trabalho" foi uma delas, e, embora simples, tem se mostrado exitosa em seu propósito de reunir informações relevantes e levá-las até o usuário das bibliotecas.

Ainda que o trabalho demande tempo dos profissionais, a colaboração permitiu não apenas que fosse inserida uma maior quantidade de informação na base, mas também que a indexação e os resumos sejam cada vez mais precisos, já que vários bibliotecários acompanham a inclusão dos termos.

Outra vantagem significativa da iniciativa foi a demonstração de que bibliotecários devem garantir o acesso à informação relevante a seus usuários, mesmo que estejam enfrentando limitações de acesso a seu acervo físico ou não contratem conteúdos digitais de editoras. O usuário, em geral, já está ambientado ao mundo digital e, diante da grande oferta de informações, precisa contar com uma curadoria de conteúdos. A biblioteca dos próximos anos deve repensar se permanecerá alheia às fontes de informação não convencionais, correndo o risco de ignorar uma produção intelectual relevante.

Como próximos passos, pretende-se ampliar o número de bibliotecas colaboradoras, em razão do crescimento contínuo da quantidade de informação pertinente a ser incluída. Além disso, é intenção de parte dos membros expandir a divulgação da base para outras bibliotecas especializadas e universitárias, uma vez que há diversas fontes 
de livre acesso que podem ser acessadas independentemente do vínculo com os Tribunais Trabalhistas.

Xie et. al. (2020) que argumentam que, durante a crise global de saúde (e também de informação), a ciência da informação deve liderar o esforço de arquivamento e armazenamento de informações digitais, especialmente de mídias sociais geradas pelo público. Portanto, considerando a recomendação dos autores, outra ação relevante é a migração dos dados para uma plataforma que permita o arquivamento a longo prazo, visto que as informações produzidas têm relevância histórica. A mudança também deve proporcionar a realização de pesquisas por campo e com o uso de operadores booleanos, mantendo a inclusão de conteúdos de forma independente e simultânea.

\section{AGRADECIMENTOS}

Cristina Carrijo Galvão pela revisão do abstract e às Bibliotecárias dos TRTs que nos enviaram informações que serviram de subsídios para o texto: Carla Torres, Adriana Pires, Marcia Pimenta, Sofia Azevedo, Rejane Façanha, Emmannuela Caldas, Elisete da Cunha e Vera Brito.

\section{REFERÊNCIAS}

ALVES, Alessandra Maria; BARBOSA, Ricardo Rodrigues. Colaboração e compartilhamento da informação no ambiente organizacional. In: ENCONTRO NACIONAL DE PESQUISA EM CIÊNCIA DA INFORMAÇÃ̃O - INOVAÇÃO E INCLUSÃO SOCIAL: questões contemporâneas da informação, 11., 2010, Rio de Janeiro. Anais... Rio de Janeiro, 2010. Disponível em: http://enancib.ibict.br/index.php/enancib/xienancib/paper/viewFile/3468/2593. Acesso em: 10 ago. 2020.

ANDRADE, Diva; VERGUEIRO, Waldomiro. Aquisição de materiais de informação. Brasília: Briquet de Lemos, 1996. 118 p.

ARAÚJO, Cátia Rosana Lemos de. Rede de colaboração entre bibliotecas da Unipampa para o compartilhamento de materiais em formato digital acessível para usuários com deficiência visual: uma proposta de implantação. Dissertação (Mestrado em Tecnologias Educacionais em Rede) - Universidade Federal de Santa Maria. Santa Maria, 2019. Disponível em: https://repositorio.ufsm.br/handle/1/19834. Acesso em: 10 ago. 2020.

BRASIL. Tribunal Superior do Trabalho. História da Justiça do Trabalho, 2020 a. Disponível em: http://www.tst.jus.br/historia-da-justica-do-trabalho. Acesso em: 4 ago. 2020.

BRASIL. Tribunal Superior do Trabalho. TST divulga levantamento oficial com número de ações relacionadas ao coronavírus na Justiça do Trabalho. Notícias do TST, Brasília, 18 jun. 2020b. Disponível em: http://www.tst.jus.br/-/tst-divulga-levantamento-oficialcom-n\%C3\%BAmero-de-a\%C3\%A7\%C3\%B5es-relacionadas-ao-coronav\%C3\%ADrus-najusti\%C3\%A7a-do-trabalho. Acesso em: 11 ago. 2020.

GOOGLE sites. O que está incluído, 2020. Suíte. Disponível em: https://gsuite.google.com.br/intl/pt-BR/products/sites/. Acesso em: 29 jul. 2020.

OLIVEIRA, Anastácia Freitas de. Particularidades do desenvolvimento de coleções jurídicas. Cadernos de Informação Jurídica, Brasília, v. 7, n. 1, p. 136-156, jan./jun. 2020. 
Disponível em: https://www.cajur.com.br/index.php/cajur/article/view/260. Acesso em: 4 ago. 2020.

ROWLEY, Jennifer. A biblioteca eletrônica. 2. ed. Brasília: Briquet de Lemos, 2002.

SARMENTO, Adriana Godoy da Silveira. Prorrogação de prazos. Destinatário: Suely Soares. [S.I.], 29 jun. 2020b. 1 mensagem eletrônica.

SILVA, Jonathas Luiz Carvalho; FREIRE, Gustavo Henrique Araújo. Um olhar sobre a origem da ciência da informação: indícios embrionários para sua caracterização identitária. Encontros Bibli: revista eletrônica de biblioteconomia e ciência da informação, v. 17, n. 33, p. 1-29, jan./abr. 2012. Disponível em: https://periodicos.ufsc.br/index.php/eb/article/view/1518-2924.2012v17n33p1. Acesso em: 11 ago. 2020.

TINÔCO, Erika Cruz da Silva. Critérios de autoridade para a realização de seleção de materiais de informação em bibliotecas especializadas. Trabalho de conclusão de curso (Bacharelado em Biblioteconomia) - Universidade de Brasília, Brasília, 2017. Disponível em:

https://bdm.unb.br/bitstream/10483/22714/1/2017_ErikaCruzDaSilvaTinoco_tcc.pdf.

Acesso em: 3 ago. 2020.

TRENDS Ajuda. Perguntas frequentes acerca do Google Trends, c2020. Google. Disponível em: https://support.google.com/trends/answer/4365533?hl=pt\&ref_topic=6248052.

Acesso em: 11 ago. 2020.

VOLPATO, Sílvia Maria Berté; BORENSTEIN, Carlos Raul. A trajetória de uma biblioteca especializada: o caso da biblioteca do curso de pós-graduação em administração da UFSC. Revista de Ciências da Administração, Florianópolis, ano 2, n. 4, set. 2000. Disponível em: https://periodicos.ufsc.br/index.php/adm/article/view/8055/7438. Acesso em: 30 jul. 2020.

XIE, Bo et. al. Global health crises are also information crises: a call to action. Journal of the Association for Information Science and Technology, 13 mar. 2020. Disponível em: https://doi.org/10.1002/asi.24357. Acesso em: 11 ago. 2020.

WINCKLER, Natália Carrão; MOLINARI, Gisele Trindade. Competição, colaboração, cooperação e coopetição: revendo os conceitos em estratégias interorganizacionais. Revista ADMpg Gestão Estratégica, v. 4, n. 1, p. 1-12, 2011.

\section{APÊNDICE - FONTES MONITORADAS}

\begin{tabular}{|l|l|}
\hline \multicolumn{1}{|c|}{ Fonte } & \multicolumn{1}{c|}{ Tipo de acesso } \\
\hline Academia brasileira de Direito do Trabalho & Livre \\
\hline ANAMATRA & Livre \\
\hline Biblioteca Digital de Revistas Síntese & Restrita \\
\hline Canal do YouTube Rodolfo Pamplona Filho & Livre \\
\hline Consultor Jurídico & Livre \\
\hline ESMPU & Livre \\
\hline Fórum Plataforma Fórum Conhecimento Jurídico & Restrita \\
\hline
\end{tabular}




\begin{tabular}{|l|l|}
\hline GEN Jurídico & Livre \\
\hline Henrique Correia & Livre \\
\hline Instituto de Direito Real & Livre \\
\hline Jorge Luiz Souto Maior & Livre \\
\hline Jota (Canal Youtube) & Livre \\
\hline La referencia & Livre \\
\hline Legislação & Livre \\
\hline Lex Magister & Restrita \\
\hline MagisterNet & Restrito \\
\hline Migalhas & Livre \\
\hline MPT & Livre \\
\hline OASIS BR & Livre \\
\hline OIT & Livre \\
\hline Os Trabalhistas & Livre \\
\hline Proview Revista dos Tribunais & Restrito \\
\hline Repositório institucional FIOCRUZ & Livre \\
\hline Revista dos Tribunais Online & Restrita \\
\hline Revista LTr digital & Restrito \\
\hline
\end{tabular}

